\title{
Información en el ámbito empresarial: una reflexión acerca de los modelos de gestión de la información
}

Informação no âmbito empresarial: uma reflexão acerca dos modelos de gestão da informação

Information on the enterprise environment: a reflection on the models of information management

Cíntia Gomes Pacheco (1) Marta Lígia Pomim Valentim (2)

(1) Faculdade de Filosofia e Ciências, Universidade Estadual Paulista Júlio de Mesquita Filho, UNESP, Campus de Marília. cintiagomesp@yahoo.com.br; (2) valentim@marilia.unesp.br

\begin{abstract}
Resumen
La información en el contexto actual asume un papel importante, proporcionando al entorno empresarial una actuación dinámica, en constante renovación y adaptarse al entorno en el que opera. En este sentido nos proponemos, partir de una revisión de la literatura, una reflexión sobre los modelos de gestión de la información para impulsar los negocios. Se revisan los modelos de Beuren (2000), Choo $(1997,1999)$ y Davenport y Prusak (1998). Se encontró que la gestión de información puede marcar una diferencia positiva muy significativa a la empresa de negocios en el contexto contemporáneo.
\end{abstract}

Palabras Clave: Información. Gestión de información. Modelos de gestión de la información.

\section{Introdução}

A sociedade atual é reflexo das constantes transformações decorrentes do fenômeno da globalização, do progresso das tecnologias de informação e comunicação (TICs), da concorrência acirrada do mercado, entre outros fatores.

Esse cenário demanda posturas proativas aos negócios que precisam se manter no mercado competitivo, uma vez que é necessário uma atuação arrojada, visando à preparação dos gestores para os possíveis obstáculos e riscos. Nesse sentido, a conscientização de que o uso da informação nos dias de hoje é primordial, no que tange a tomada de decisão estratégica e o planejamento de ações, torna-se cada vez mais importante.

No âmbito empresarial, essa noção da importância da informação é perceptível. Uma vez utilizada como um recurso estratégico e bem gerenciada, pode propiciar o bom andamento dos negócios. A informação pode ser considerada como um fator estruturante e um instrumento essencial para a gestão empresarial (Moresi, 2001).

\begin{abstract}
In the present context the information assumes a major role, providing to the business environment a dynamic performance that is constantly renewing and adapting itself to the environment in which it operates. In that sense we aimed, through literature, a reflection the models of information management for business. Were review the models of Beuren (2000), Choo (1997, 1999) and Davenport and Prusak (1998). We conclude that information management can provide a significant positive differential to business in the contemporary context.
\end{abstract}

Keywords: Information. Information Management. Models of Information Management.

A informação é fundamental no apoio às estratégias e processos de tomada de decisão, bem como no controle das operações empresariais. Sua utilização representa uma intervenção no processo de gestão, podendo, inclusive, provocar mudança organizacional, à medida que afeta os diversos elementos que compõem o sistema de gestão. Esse recurso vital da organização, quando devidamente estruturado, integra as funções das várias unidades da empresa, por meio dos diversos sistemas organizacionais (Beuren, 2000, p.43).

Considerada em duas perspectivas, a informação pode indicar alternativas inovadoras para o processo de planejamento estratégico, apoiando a execução de objetivos, metas e ações, e também ser insumo vital que incorpora as próprias estratégias definidas (Beuren, 2000).

Nesse sentido, foi realizado um levantamento na literatura acerca dos modelos de gestão da informação enfocando o uso da informação como alicerce imprescindível para a gestão contemporânea de ambientes empresariais.

\section{Gestão da Informação (GI)}

A Gestão da Informação (GI) pode ser considerada um conjunto de atividades para 
[...] prospectar/monitorar, selecionar, filtrar, tratar, agregar valor e disseminar informação, bem como para aplicar métodos, técnicas, instrumentos e ferramentas que apóiem esse conjunto de atividades (Valentim, 2006, p.18).

Ponjuán Dante (2007, p.19, tradução nossa) compreende a gestão da informação - Gl como:

[...] o processo pelo qual se obtém, desdobra e utiliza recursos básicos (econômicos, físicos, humanos, materiais) para gerenciar a informação interna e para a sociedade que serve. Tem como elemento básico a gestão do ciclo de vida deste recurso o que acontece em qualquer organização. É própria também de unidades especializadas que lidam com este recurso de forma intensiva, denominadas unidades de informação.

De acordo com a autora, a gestão da informação é fundamentalmente regida por dois princípios, quais sejam a teoria dos sistemas e a teoria do ciclo de vida.

Um sistema de informação está integrado por um conjunto de componentes, os quais armazenam, processam e distribuem informação. A gestão da informação é a gestão desenvolvida em um sistema de informação que tem como propósito obter saídas de informação. Além disso, está associada às dimensões do ambiente, dos processos, das pessoas, da tecnologia, da infraestrutura e dos produtos e serviços (Ponjuán Dante, 2007).

Os processos de agregação de valor à informação também são identificados como básicos para o profissional em gestão da informação, incluindo-se aí as habilidades de análise, condensação, interpretação, representação e estratégias de busca e apresentação/formatação da informação - tendo em vista os diferentes suportes, canais que esta informação possa estar (e ser) disponibilizada, assim como o(s) tipo(s) de informação que é objeto de tal atividade (ou seja, textual, sonoro, numérico, visual etc., ou ainda, a reunião de vários tipos, haja vista a demanda identificada) (Marchiori, 2002, p.75).

A gestão da informação atua alicerçada aos fluxos formais de informação da empresa, com foco no negócio da organização, agindo restritamente às informações explicitadas em algum suporte, podendo este ser impresso, eletrônico, digital ou de outro tipo (Valentim, 2006).

\section{Modelos de Gestão da Informação}

Para assegurar o valor estratégico da informação, Beuren (2000) afirma que na fase de planejamento organizacional é necessário desenvolver um processo coordenado abrangendo todas as fases do gerenciamento da informação. A autora afirma que deve existir uma compreensão ampla da seqüência das tarefas para o êxito do processo de gestão da informação. Desse modo, pontuar-se-á algumas questões relacionadas a cada uma dessas tarefas:

- Identificação de necessidades e requisitos de informação: Consiste no conhecimento das diversas alternativas que podem tornar a informação mais estratégica para seus usuários. A quantidade de fontes deverá ser superior quanto mais amplo for o número de variáveis críticas contidas no ambiente que se queira representar. Outra ressalva é que a variedade de informações necessárias para a gestão tende a crescer na medida em que aumenta a complexidade do ambiente organizacional;

- Coleta/entrada de informação: Essa fase requer uma estrutura formal ou informal para a entrada, filtragem e coleta de informação. Essa estrutura visa, inicialmente, identificação e compreensão das informações necessárias;

- Classificação e armazenamento da informação: Tem como foco o usuário, uma vez que a interface dele com o sistema precisa considerar suas percepções no momento de interação. Quanto à classificação da informação, as informações poderão ser acessadas pelos usuários através de um sumário/índice, indicando as diferentes classes das informações. A classificação e o armazenamento precisam ser refletidos de maneira seletiva propiciando o uso efetivo do sistema de informação;

- Tratamento e apresentação da informação: Essa fase atua em conjunto com os processos de classificação e armazenamento dos dados e informações. No entanto, essa atividade deve ser previamente planejada a fim de proporcionar um trabalho diferenciado, que permite buscar por metodologias e representações distintas, permitindo assim, deixar disponível no sistema informações das diferentes percepções de necessidades informacionais, contendo uma variedade de fontes e estilos de informação;

- Desenvolvimento de produtos e serviços de informação: Essa fase é de extrema importância, em que são produzidos os produtos e serviços de informação a fim de auxiliar na execução de uma estratégia organizacional. Esse processo pode ser otimizado a partir da maior participação dos usuários do sistema e as interações com diferentes formações profissionais;

- Demais tarefas do processo de gestão da informação: Dando seqüência ao processo de gerenciamento da informação, após a e- 
laboração dos produtos e serviços, é necessário atentar para as atividades de distribuição e disseminação da informação, bem como da análise e do uso da informação. A autora atenta que todos os processos de gestão da informação devem contar com os usuários, permitindo um melhor aproveitamento dos processos. Dessa forma, o gestor da informação pode criar um dispositivo de interface em que se estabeleça a ligação com os usuários e entre as pessoas responsáveis em distribuir e disseminar a informação. A autora aponta também que seria interessante a criação de uma rede formal de comunicação ou a criação de unidades de informação que ficassem encarregadas pelo levantamento das necessidades informacionais das lideranças ou grupos de usuários.

É importante salientar que os processos devem ser sempre refletidos, a fim de garantir um gerenciamento da informação enfocado em seus usuários.

Choo (1997) propõe, baseado em Choo (1995), Davenport (1993) e McGee e Prusak (1993), que a gestão da informação deve ser compreendida como um ciclo contínuo de cinco processos relacionados. Assim, reproduz-se na Figura 1 o modelo de gestão da informação proposto pelo autor supracitado:

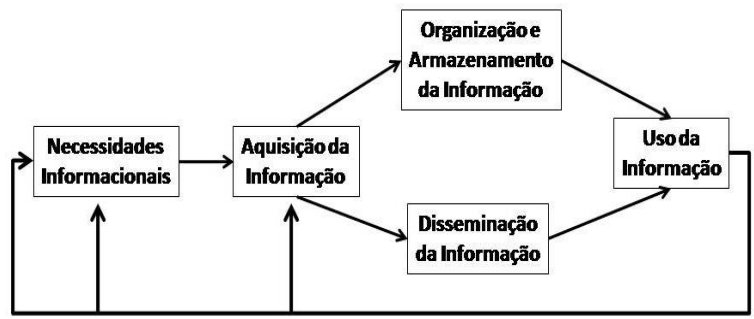

Figura 1. Modelo de Gestão da Informação (adaptado de Choo, 1997, p. 5).

Choo (1997) comenta este modelo de gestão da informação, iniciando pelo processo de uso da informação. Destaca que as organizações usam a informação em três arenas estratégicas: criação de significado (sensemaking), construção de conhecimentos e tomada de decisão.

O autor comenta a respeito do processo de identificação das necessidades de informação junto às pessoas. As necessidades informacionais no âmbito organizacional estão relacionadas aos problemas, incertezas e ambigüidades encontradas em determinadas situações organizacionais. Essas situações e experiências são resultados não apenas do assunto a ser questionado, mas também em relação às interações de um número de fatores contextuais, tais como os relativos à cultura da organização.

A apropriação da informação envolve dois aspectos, por um lado a organização precisa de informações que reflitam a amplitude e a diversidade das suas preocupações sobre mudanças e acontecimentos do ambiente externo e, por outro lado, é necessário reconhecer que a atenção e a capacidade cognitiva do ser humano é limitada de modo que as organizações selecionem necessariamente as mensagens que as atendem. A seleção e a utilização de fontes de informação devem ser planejadas e monitoradas continuamente como qualquer outro recurso vital para a organização (Choo, 1997).

A gestão da informação parte da informação que é adquirida ou gerada pela/na organização, passa pelo processo de filtragem, análise, organização e armazenamento em arquivos, bases de dados entre outros sistemas de informação, visando facilitar o compartilhamento e disseminação da informação. A forma com que a informação é armazenada reflete a percepção e a representação do ambiente da organização, incluindo a sua rotulagem e as relações dos assuntos, transações e medição de desempenho. Além disso, a flexibilidade dos sistemas de armazenagem permite explorar padrões e conexões pelos usuários (Choo, 1997).

A disseminação da informação é o processo pelo qual a informação é divulgada e formalmente circulada na organização, direcionada a pessoas ou grupo de pessoas, considerando o tempo certo, local, formato entre outros aspectos. Essa ação continuada possibilita muitas consequências positivas, como a aprendizagem organizacional, a construção de novo conhecimento, a inovação etc. (Choo, 1997).

Na Figura 2, Choo (1999) apresenta uma nova versão de gestão da informação, baseada na Figura 1 apresentada anteriormente, inserindo o processo de comportamento informacional de maneira adaptativa: 


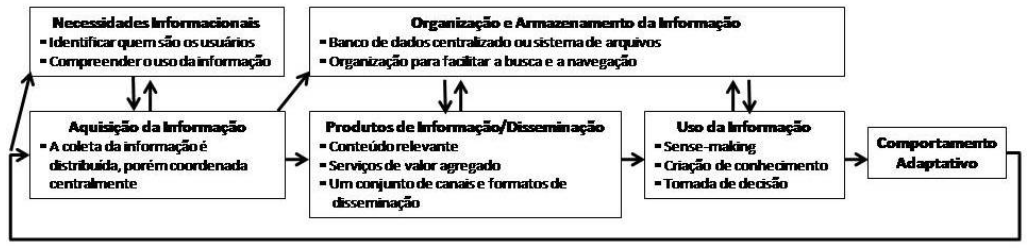

Figura 2. Gestão da Informação no Monitoramento Informacional (adaptado de Choo, 1999, p. 24).

O comportamento adaptativo refere-se ao feedback dos processos mencionados relacionados à informação. Esses processos, quando estimulados na organização, podem provocar uma mudança no comportamento individual e coletivo da organização, adaptando a uma nova postura de lidar com a informação nesse contexto.

Para auxiliar as organizações no processo de gerenciamento da informação no âmbito organizacional, Davenport e Prusak (1998) propõem um modelo ecológico de informação. O modelo compreende os ambientes informacional, organizacional e externo numa perspectiva holística, ou seja, todos os elementos relativos à organização atuam integrados de acordo com a concepção sistêmica. Os autores enfatizam a importância da informação como um recurso da gestão. Na Figura 3 reproduz-se o modelo ecológico proposto pelos autores:

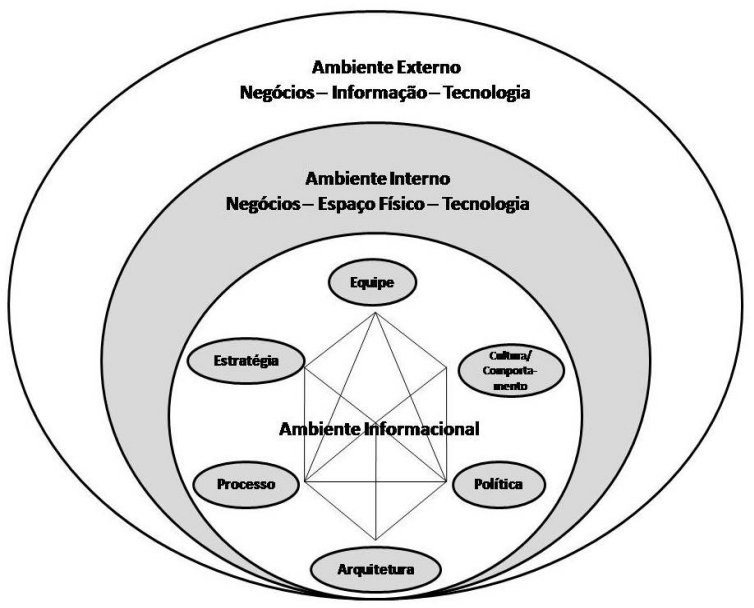

Figura 3. Um Modelo Ecológico para o Gerenciamento da Informação - (Davenport, Prusak, 1998, p.51).

Para os autores, o ambiente informacional constitui-se no núcleo da abordagem holística, que se origina do ambiente organizacional, compreendido como sendo composto pelos ambientes externo e interno.

Constata-se a partir dos modelos de gestão da informação apresentados por Beuren (2000), Choo (1997; 1999) e Davenport e Prusak (1998) a importância da informação como um recurso estratégico vital da organização.

\section{Considerações Finais}

A informação em ambientes empresarias assume um papel de suma importância, pois permeia todas as atividades organizacionais. As empresas precisam se adequar constantemente às manifestações do ambiente externo, e também do próprio ambiente interno, para manter seus negócios produtivos e lucrativos.

Uma gestão organizacional que tem como base a informação se torna imprescindivel atualmente, pois propicia uma atuação amparada em informação e conhecimento concernente ao ramo de negócio, auxiliando o planejamento de curto, médio e longo prazo, além de potencializar o processo de tomada de decisão.

A gestão da informação pode ser considerada uma atividade essencial de sobrevivência das organizações no cenário atual, cada vez mais instável e complexo, à medida que as organizações percebem o ganho significativo que podem adquirir atuando nessa perspectiva.

\section{Referências}

Beuren, I. M. (2000). Gerenciamento da Informação: um recurso estratégico no processo de gestão empresarial. São Paulo: Atlas, 2000. 104

Choo, C. W. (1997). Organizations as "Information- Use Systems": a process model of information management. University of Amsterdam, Department of Information Management: PrimaVera Working Paper No., 1997.

Choo, W. C. (1995). Information Management for the Intelligent Organization: the art of scanning the environment. Medford, NJ: Information Today, Inc, 1995.

Choo, C. W. (1999). The art of scanning the environment. // Bullentin of the American Society for Information Science. 25:3 (1999) 13-19. http://choo.fis.utoronto.ca/ (2009-07-04).

Davenport, T. H. (1993). Process Innovation: reengineering work through information technology. Boston, MA: Harward Business School Press, 1993.

Davenport, T. H.; Prusak, L. (1998). Ecologia da informação: por que só a tecnologia não basta para o sucesso na era da informação. São Paulo: Futura, 1998. 316.

Marchiori, P. Z. (2002). A ciência e a gestão da informação: compatibilidades no espaço profissional. // Ciência da informação. Brasília. 31:2 (2002) 72-79. http://revista. 
ibict.br/index.php/ciinf/article/viewArticle/159 (2008-1110).

McGee, J. V.; Prusak, L. (1993) Managing Information Strategically. New York, NY: John Wiley \& Sons, 1993.

Moresi, E. A. D. (2001). Gestão da Informação e do conhecimento. // Tarapanoff, K. Inteligência organizacional e competitiva. Brasília: Editora da Universidade de Brasília, 2001. 344.

Ponjuán Dante, G. (2007). Gestión de información: dimensiones e implementación para el êxito organizacional. España e Portugal: Trea, S. L., 2007. 158.

Valentim, M. L. P. (2006). Processo de inteligência competitiva organizacional. // Valentim, M. L. P. (Org.). Informação, conhecimento e inteligência organizacional. Marília: Fundepe Editora, 2006 9-24.

Recibido: 20-04-2010.

Aceptado: 20-04-2010. 
